\title{
Video-assisted thoracoscopic surgery versus robot-assisted thoracoscopic surgery versus thoracotomy for early-stage lung cancer
}

\author{
Trevor C. Upham, MD, and Mark W. Onaitis, MD
}

\author{
From the Division of Cardiovascular and Thoracic Surgery, University of California San Diego Medical Center, \\ San Diego, Calif. \\ Received for publication July 27, 2017; revisions received Feb 7, 2018; accepted for publication Feb 17, 2018. \\ Address for reprints: Mark W. Onaitis, MD, Division of Cardiovascular and Thoracic Surgery, University of Cal- \\ ifornia San Diego Medical Center, San Diego, CA (E-mail: monaitis@ucsd.edu). \\ J Thorac Cardiovasc Surg 2018;156:365-8 \\ $0022-5223 / \$ 36.00$ \\ Copyright (c) 2018 by The American Association for Thoracic Surgery \\ https://doi.org/10.1016/j.jtcvs.2018.02.064
}

Feature Editor's Note-Thoracic surgery has experienced a rapid evolution of minimally invasive surgical techniques for lobectomy that have become widely adopted in the care of patients with early-stage lung cancer. On display are thoracoscopic lobectomy, uniportal thoracoscopic lobectomy, robotic-assisted thoracoscopic lobectomy, "microlobectomy," and even "awake" thoracoscopic lobectomy, and the data supporting the feasibility, safety, and efficacy of these techniques are emerging. It can now be considered fact that minimally invasive lobectomy, compared with lobectomy by thoracotomy, results in improved short-term outcomes, including pain, functional recovery, and surgical morbidity. However, the impact of minimally invasive lobectomy on oncologic outcomes requires time. The result is a period of uncertainty during which these techniques can root themselves in clinical practice and that permits an opportunity for innovation to outpace standards of care. During this period, the operator must embrace responsibility in the application of these technologies to the care of their patients. In this article, Onaitis and Upham provide a balanced and comprehensive account of the short-term outcomes, oncologic outcomes, and cost considerations of thoracoscopic lobectomy, robotic-assisted thoracoscopic lobectomy, and lobectomy by thoracotomy. One critical point that our readers will appreciate is that favorable oncologic outcomes are achievable by minimally invasive lobectomy. Referenced in the accompanying article are data from the several series that support this statement, and behind these series are thoracic surgeons who responsibly adopt these minimally invasive technologies into their practice through ongoing evaluation of their operative technique, care pathways, methodology for self-assessment, and outcomes reporting. This primer provides both a cogent framework for understanding and advancing this field, and an important update of our current knowledge of surgery for early-stage lung cancer.

Bryan M. Burt, MD

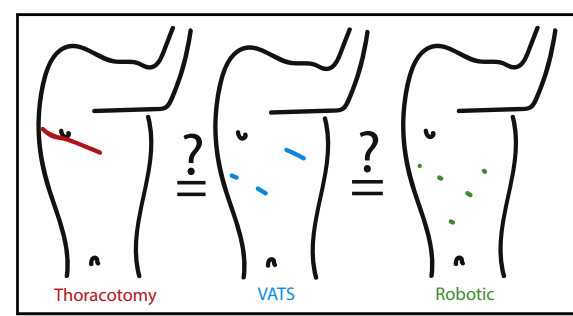

The ideal approach for lobectomy is unknown

\section{Central Message}

The literature demonstrates that minimally invasive operations improve short-term outcomes, but surgeons must examine oncologic outcomes to determine the optimal approach.

See Editorial Commentary page 369.

See Editorial page 363.
Video-assisted thoracoscopic surgery (VATS) and robotassisted thoracoscopic surgery (RATS) have provided methods of treating thoracic malignancies that are less invasive than thoracotomy. Many outcome advantages have been cited in supporting VATS and RATS over thoracotomy for patients with stage I lung cancer. However, no large randomized, prospective trial has compared VATS or RATS with thoracotomy, and few surgeons have true equipoise. In addition, although some data exist, the efficacy of minimally invasive lobectomy in higher-stage disease is unclear. Consequently, we must honestly evaluate the literature in combination with our own experiences to choose the approach that maximizes survival against potential comorbidity.

Provision of a lobectomy for a patient with a lung malignancy must be done with the goal of optimizing the overall survival of the patient. This involves 2 critical principles of surgical management of malignancies: obtaining a negative margin with a low rate of locoregional recurrence and obtaining sufficient lymph node tissue for accurate staging. In addition, many nononcologic factors must be considered when comparing lobectomy strategies. Morbidity and length of stay should be as low as possible. In addition, cost must be considered in the evolving world of healthcare. This review will evaluate the literature with respect to these issues. Rather than discuss each approach 
against the others, we will discuss oncologic efficacy across the approaches and then highlight nononcologic outcomes.

\section{ONCOLOGIC GOALS}

The landmark Lung Cancer Study Group article by Ginsberg and Rubinstein ${ }^{1}$ in 1995 firmly established anatomic lobectomy as the standard of care for resectable early-stage (cT1N0) non-small cell lung cancer. The resections in this study were performed using a thoracotomy approach, and locoregional recurrence was significantly lower than with sublobar resection. ${ }^{1}$ This increased recurrence was undoubtedly due to inadequate margins or inability to clear intraparenchymal/hilar lymph nodes with the sublobar approaches. In fact, patients with limited resection experienced a doubling of the local recurrence rate. Although this review will not consider sublobar resection, we anticipate that if minimally invasive approaches compromise margins or lymph node harvest, similar increases in recurrence rates and potentially survival will be reported. In the literature reported thus far, this does not appear to be the case.

In regard to lymph node harvest, several recent studies have compared nodal upstaging in patients with clinical N0 between VATS and open approaches. A singleinstitution report from Stanford and a report from the Danish national database have demonstrated decreased nodal upstaging rates with VATS., ${ }^{2,3}$ Boffa and colleagues ${ }^{4}$ have reported a similar phenomenon using the Society of Thoracic Surgeons database. However, the latter study clearly demonstrated that surgeons who perform a high percentage of lobectomies thoracoscopically have excellent nodal upstaging that is equal to the thoracotomy group. A recent study from the Society of Thoracic Surgeons database has also demonstrated no difference in nodal upstaging between approaches including robotics. ${ }^{5} \mathrm{~A}$ single-institution study that propensity matched open lobectomy and robotic lobectomy revealed an increase in median nodes evaluated after robotic lobectomy. ${ }^{6}$ Therefore, it is reasonable to conclude that lymph node harvest may be accomplished using any approach, and each surgeon must honestly and carefully evaluate his or her own results to make sure that at least 10 nodes and at least 3 mediastinal stations (and preferably more in addition to at least 3 hilar stations) are sampled well. ${ }^{7}$

Along with upstaging of patients with N0, analysis of survival of patients with stage I lung cancer may allow comparison between techniques. Many studies continue to show noninferior results of RATS and VATS when compared with open lobectomy for early non-small cell lung cancer. ${ }^{8}$ However, one meta-analysis showed an increase in overall survival of VATS lobectomy over open lobectomy of $5 \%$ at 1 year and $17 \%$ at 4 years. ${ }^{9}$
Other meta-analyses have also shown an increase in overall survival of VATS lobectomy when compared with open lobectomy. ${ }^{10}$ The improvement in overall survival seen retrospectively in VATS has been speculated to be related to the less immunosuppressive nature of a minimally invasive lobectomy. ${ }^{11}$ An early report from 3 high-volume RATS centers has also shown excellent stage I-specific survival. ${ }^{12}$ These results clearly are subject to selection bias, but we can conclude that each approach may yield excellent survival. More mature data are needed regarding RATS survival across a population of surgeons. Although the proposed immunoprotective effect of minimally invasive approaches is intriguing, more data are clearly needed before a definitive conclusion can be made.

A learning curve has been analyzed with respect to VATS and robotic approaches. This has been primarily estimated by stabilization of time to complete the lobectomy. As more surgeons pursue minimally invasive approaches, perhaps an "oncologic learning curve" will be analyzed in which the number of cases to equivalent nodal sampling and dissection to thoracotomy is analyzed.

Finally, because effective adjuvant therapy exists for patients with large tumors and node-positive tumors, and this seems to depend on the dose administered, the ability to "bounce back" quickly from lobectomy may lead to improved adjuvant therapy delivery. A small singleinstitution study demonstrated that those undergoing VATS lobectomy have increased the ability to be administered adjuvant therapy and to receive more of the planned regimens. ${ }^{13}$ However, others have refuted this finding using a large national database. ${ }^{14}$ Again, although an answer may become clear as databases and individual experiences mature, approaches to reduce morbidity with an eye toward adjuvant treatment will be important as adjuvant therapy continues to improve. This effect may be magnified in the growing elderly population who tolerate VATS better than an open thoracotomy. ${ }^{15}$

\section{NONONCOLOGIC OUTCOMES}

The Cancer and Leukemia Group B has defined a VATS lobectomy as one with videoscopic guidance and anatomic hilar vascular, bronchial, and lymphatic dissection using 2 or 3 ports and without rib spreading. ${ }^{8}$ Problems with comparison of data for morbidity begin with variation from this definition. Surgeons at different hospitals perform what is described as a VATS lobectomy that is often variable within and outside of this definition. However, multiple multi-institution and single institution experiences describe decreased morbidity as a strong driver in favor of minimally invasive approaches.

Pooling multiple studies comparing VATS with open lobectomy for early non-small cell lung cancer has 
consistently shown a reduction in overall perioperative morbidity. A systemic review reported that the overall complication rate of VATS lobectomy was $16.4 \%$ compared with $31.2 \%$ in the open lobectomy group. In this same study, chest tube duration was 4.2 versus 5.7 days, and length of stay was 8.3 versus 13.3 days in the VATS versus open lobectomy group. In other meta-analyses, blood use, postoperative vital capacity loss, and time to return to full activity were reduced in the VATS lobectomy group when compared with open lobectomy. ${ }^{16}$ In smaller series, RATS lobectomy has been demonstrated to be feasible and safe with comparable length of stay, major morbidity, and in-hospital mortality. ${ }^{12,17}$ Although many may argue that they achieve low morbidity with open lobectomy, the preponderance of the data demonstrate advantages to the minimally invasive approaches.

Decreased postoperative pain from VATS techniques has been a well-accepted advantage of VATS lobectomy, with patients requiring fewer narcotics and having lower perceived pain. ${ }^{18}$ Theoretically, the decreased pain should lead to improved pulmonary toilet and fewer respiratory complications. In a large retrospective analysis of the Society of Thoracic Surgeons database, Ceppa and colleagues ${ }^{19}$ demonstrated decreased incidence of atelectasis requiring bronchoscopy, postoperative pneumonia, adult respiratory distress syndrome, initial ventilator support of more than 48 hours, and reintubation. These differences are especially acute in patients with compromised respiratory function. Although similar comparisons have not been published for robotic approaches, lack of rib spreading seems to improve postoperative respiratory outcomes.

Another common complication that affects discharge of patients after lobectomy is atrial fibrillation. Some studies have demonstrated that atrial fibrillation is statistically less common in the VATS group compared with the open cohort. ${ }^{9}$ However, other studies have shown no difference in atrial fibrillation comparing VATS with open lobectomy. ${ }^{20}$ Variability in reported atrial fibrillation rates is common because individual practitioners and hospitals differ with respect to telemetry, prophylaxis, and treatment. However, it seems clear that across the population of practices, atrial fibrillation rates are lower. Whether this is due to reduced systemic inflammatory response or operative differences or merely the reduced length of stay with minimally invasive lobectomy remains to be seen.

As mentioned earlier, some single and multi-institution analyses have looked at specific populations who may benefit in the short-term from potentially less morbid minimally invasive operations. For example, the elderly have been shown to particularly benefit from a VATS lobectomy. ${ }^{21}$ Furthermore, a large retrospective review demonstrated particular benefit of VATS over thoracotomy in those patients with a forced expiratory volume in 1 second of less than $60 \%$ predicted. ${ }^{19}$ As experiences improve and long-term survival is addressed, ${ }^{22}$ further identification of subgroups with particular benefit may occur.

\section{COST DIFFERENCES}

In the consideration of minimally invasive techniques, cost is a significant factor. Studies have shown thoracotomy to be more expensive than VATS in terms of overall hospital cost despite a higher operating room cost for VATS. This effect was similarly identified, albeit with a smaller magnitude, for RATS. This is thought to relate to decreased length of stay and decreased morbidity of VATS and RATS. ${ }^{23}$ One of the largest retrospective analyses by Swanson and colleagues ${ }^{24}$ concluded that VATS lobectomy had a shorter length of stay by 1.68 days, was $\$ 700$ cheaper despite being 20 minutes longer in the operating room, and caused lower morbidity. However, this study demonstrates the need for further modern studies. ${ }^{24}$ In addition to the standard demographic matches, goals for future comparisons (internally or for publication) for the patient with cancer should match for tumor stage and oncologic treatment algorithm.

What is certain is that disposables are typically used more frequently and may increase operative cost in VATS and especially in RATS. Robotic staplers that come with a premium price further augment the already high cost of robotic disposables from a single supplier. ${ }^{25}$ In addition, robotic instruments have a limited life span, and at least 3 must be opened per case. Furthermore, there are learning curves with both VATS and RATS lobectomies that lead to longer operating room times. RATS lobectomy operating times may improve over time with surgeon experience. ${ }^{26}$ However, operating times have still proven to be longer than VATS lobectomies even well out on the learning curve. ${ }^{27}$

Finally, the cost of nights spent in critical care units and in the hospital are metrics evaluated when comparing lobectomy strategies. Robotic lobectomy has been shown to decrease overall hospital cost compared with open lobectomy. ${ }^{28}$ However, in this study, the nonrobotic cases spent time in the intensive care unit while the robotic cases did not. Hopefully, future studies of cost will match patients demographically, control for hospital unit use, and include long-term oncologic costs.

\section{CONCLUSIONS}

Ideal statistical comparisons of VATS, RATS, and open lobectomy in terms of oncologic outcomes, morbidity, and cost will continue to be difficult to achieve. Intuitively, everyone would support less-invasive surgery via any approach if it were able to provide the expected decrease in morbidity and allow for at least equivalent if not improved oncologic outcomes. Each surgeon must evaluate his or her own outcomes in these domains. 


\section{Conflict of Interest Statement}

Authors have nothing to disclose with regard to commercial support.

\section{References}

1. Ginsberg RJ, Rubinstein LV, Lung Cancer Study Group. Randomized trial of lobectomy versus limited resection for T1 N0 non-small cell lung cancer. Ann Thorac Surg. 1995;60:615-23.

2. Merritt RE, Hoang CD, Shrager JB. Lymph node evaluation achieved by open lobectomy compared with thoracoscopic lobectomy for NO lung cancer. Ann Thorac Surg. 2013;96:1171-7.

3. Licht PB, Jørgensen OD, Ladegaard L, Jakobsen E. A national study of nodal upstaging after thoracoscopic versus open lobectomy for clinical stage I lung cancer. Ann Thorac Surg. 2013;96:943-9.

4. Boffa DJ, Kosinski AS, Paul S, Mitchell J, Onaitis MW. Lymph node evaluation by open or video-assisted approaches in 11,500 anatomic lung cancer resections. Ann Thorac Surg. 2012;94:347-53.

5. Wilson JL, Louie BE, Kim S, Cerfolio RJ, Park BJ, Farivar AS, et al. Comparison of video-assisted thoracoscopic surgery and robotic approaches for clinical stage I and stage II non-small cell lung cancer using the Society of Thoracic Surgeons Database. Ann Thorac Surg. 2016;102:917-24.

6. Wilson JL, Louie BE, Cerfolio RJ, Park BJ, Vallieres E, Aye RW, et al. The prevalence of nodal upstaging during robotic lung resection in early stage non-small cell lung cancer. Ann Thorac Surg. 2014;97:1901-6.

7. Whitson BA, Groth SS, Maddaus MA. Surgical assessment and intraoperative management of mediastinal lymph nodes in non-small cell lung cancer. Ann Thorac Surg. 2007;84:1059-65.

8. Swanson SJ, Herndon JE, D’Amico TA, Demmy TL, McKenna RJ, Green MR, et al. Video-assisted thoracic surgery lobectomy: report of CALGB 39802-a prospective, multi-institution feasibility study. J Clin Oncol. 2007;25:4993-7.

9. Whitson BA, Groth SS, Duval SJ, Swanson SJ, Maddaus MA. Surgery for earlystage non small cell lung cancer: a systemic review of the video-assisted thoracoscopic surgery versus thoracotomy approaches to lobectomy. Ann Thorac Surg. 2008;86:2008-18.

10. Yan TD, Black D, Bannon PG, McCaughan BC. Systematic review and metaanalysis of randomized and non randomized trials on safety and efficacy of video-assisted thoracic surgery lobectomy for early-state non-small cell lung cancer. J Clin Oncol. 2009;27:2553-62.

11. Whitson BA, D'Cunha J, Maddaus MA. Minimally invasive cancer surgery improves patient survival through less perioperative immunosuppression. Med Hypothesis. 2007; 68:1328-32.

12. Park BJ. Robotic lobectomy for non-small cell lung cancer (NSCLC): multicenter registry study of long-term oncologic results. Ann Cardiothorac Surg. 2012;1:24-6.
13. Petersen RP, Pham D, Burfeind WR, Hanish SI, Toloza EM, Harpole DH, et al. Thoracoscopic lobectomy facilitates the delivery of chemotherapy after resection for lung cancer. Ann Thorac Surg. 2007;83:1245-50.

14. Licht PB, Schytte T, Jakobsen E. Adjuvant chemotherapy compliance is not superior after thoracoscopic lobectomy. Ann Thorac Surg. 2014;98:411-5.

15. McKenna RJ Jr, Houck WV. New approached to the minimally invasive treatment of lung cancer. Curr Opin Pulm Med. 2005;11:282-6.

16. Cheng D, Downey RJ, Kernstine K, Stanbridge R, Shennib H, Wolf R, et al. Video-assisted thoracic surgery in lung cancer resection: a meta-analysis and systematic review of controlled trials. Innovations. 2007;2:261-92.

17. Ye X, Xie L, Chen G, Ben XS. Robotic thoracic surgery versus video-assisted thoracic surgery for lung cancer: a meta-analysis. Interact Cardiovasc Thorac Surg. 2015;21:409-14.

18. Landreneau RJ, Hazelrigg SR, Mack MJ, Dowling RD, Burke D, Gavlick J, et al. Postoperative pain-related morbidity: video-assisted thoracic surgery versus thoracotomy. Ann Thorac Surg. 1993;56:1285-9.

19. Ceppa DP, Kosinski AS, Berry MF, Tong BC, Harpole DH, Mitchell JD, et al. Thoracoscopic lobectomy has increasing benefit in patients with poor pulmonary function: a Society of Thoracic Surgeons database analysis. Ann Surg. 2012;256:487-93.

20. Park BJ, Zhang H, Rusch VW, Amar D. Video-assisted thoracic does not reduce the incidence of postoperative atrial fibrillation after pulmonary lobectomy. $J$ Thorac Cardiovasc Surg. 2007;133:775-9.

21. Cannaneo SM, Park BJ, Wilton AS, Seshan V, Bains MS, Downey RJ, et al. Use of video-assisted thoracic surgery for lobectomy in the elderly results in fewer complications. Ann Thorac Surg. 2008;85:231-5.

22. Fernandez FG, Furnary AP, Kosinski AS, Onaitis MW, Kim S, Boffa D, et al. Longitudinal follow-up of lung cancer resection from the Society of Thoracic Surgeons General Thoracic Surgery Database in patients 65 years and older. Ann Thorac Surg. 2016;101:2067-76.

23. Park BJ, Flores RM. Cost comparison of robotic, video-assisted thoracic surgery and thoracotomy approaches to pulmonary lobectomy. Thorac Surg Clin. 2008; 18:297-300.

24. Swanson SJ, Meyers BF, Gunnarsson CL, Moore M, Howington JA, Maddaus MA, et al. Video assisted thoracoscopic lobectomy is less costly and morbid than open lobectomy: a retrospective multi institutional database analysis. Ann Thorac Surg. 2012;93:1027-32.

25. Park BJ. Cost concerns for robotic thoracic surgery. Ann Cardiothorac Surg. 2012;1:56-8.

26. Veronesi G, Agoglia BG, Melfi F, Maisonneuve P, Berlotti R, Bianchi PP, et al. Experience with robotic lobectomy for lung cancer. Innovations (Phila). 2011; 6:355-60.

27. Jang H-J, Lee H-S, Park SY, Zo JI. Comparison of the early robot-assisted lobectomy experience to video-assisted thoracic surgery lobectomy for lung cancer. Innovations (Phila). 2011;6:305-10.

28. Dylewski MR, Ohaeto AC, Pereira JF. Pulmonary resection using a total endoscopic robotic video-assisted approach. Semin Thorac Cardiovasc Surg. 2011; $23: 36-42$. 